Gut, 1973, 6, 905-909

\title{
A new technique for examining intestinal biopsies
}

\author{
B. L. CHAPMAN, K. HENRY, F. PAICE, J. S. STEWART, AND N. F. COGHILL
}

From the Department of Medicine, West Middlesex Hospital, Isleworth, Middlesex, the Department of Morbid Anatomy, Royal Postgraduate Medical School, Hammersmith Hospital, and the Medical Research Council Cyclotron Unit, Hammersmith Hospital, London

SUMMARY A new technique for measuring changes in the architecture of the small intestinal mucosa is described using a modification of the technique of television image analysis to measure the areas occupied by the surface and crypt epithelium in proximal jejunal biopsies. The ratios of these two areas to each other were then calculated. In 12 control mucosae, the mean ratio $( \pm S D)$ was $2 \cdot 27 \pm 0.41$. In 12 untreated flat mucosae, by contrast, the mean ratio was only $0.24 \pm 0.07$. This ten-fold difference, which was highly significant $(\mathbf{P}<0.001)$, was greater than that for any similar measurements previously reported. This technique is intended for the measurement of changes in the mucosa too small for existing techniques to detect reliably rather than for the diagnosis of coeliac disease.

A new technique for measuring changes in the architecture of the small intestinal mucosa has been developed to investigate the long-term response of patients with adult coeliac disease to treatment with a gluten-free diet. This technique utilizes the observation of Doniach and Shiner (1957) that in this condition there is a decrease in the amount of surface epithelium and an increase in that of crypt epithelium. One of us (K.H.) was largely responsible for developing the technique of measuring the areas of surface and crypt epithelium with a television image analyser, and the use of their ratio as an index to mucosal change.

We sought a new technique for the following reasons. Some of the existing techniques measure single dimensions of the mucosal architecture such as villous height and width (Doniach and Shiner, 1957), mucosal thickness (Shiner and Doniach, 1960), and surface cell height (Shiner and Doniach, 1960); others involve indirect measurements of the length of the surface epithelium (Butterworth and Perez-Santiago, 1958; Rubin, Brandborg, Phelps, and Taylor, 1960a; Cameron, Astley, Hallswell, Rawson, Miller, French, and Hubble, 1962; Madanagopalan, Shiner, and Rowe, 1965; Swanson and Thomassen, 1965), and others make use of indices which depend on villous architecture (Cameron et al, 1962; Madanagopalan et al, 1965; Swanson and Thomassen, 1965). All of these measurements

Received for publication 3 July 1973. have wide ranges of values in both control (Doniach and Shiner, 1957; Butterworth and Perez-Santiago, 1958; Rubin et al, 1960a and b; Shiner and Doniach, 1960; Chacko, Job, Johnson, and Baker, 1961; Cameron et al, 1962; Jos, 1962; Yardley, Bayless, Norton, and Hendrix, 1962; Astaldi, Conrad, Ratto, and Costa, 1965; Madanagopalan et al, 1965; Swanson and Thomassen, 1965; Stewart, Pollock, Hoffbrand, Mollin, and Booth, 1967; Pollock, Nagle, Jeejeebhoy, and Coghill, 1970) and coeliac (Rubin et al, 1960a; Shiner and Doniach, 1960; Chacko et al, 1961; Cameron et al, 1962; Jos, 1962; Yardley et al, 1962; Bolt, Parrish, French, and Pollard, 1964; Madanagopalan et al, 1965; Stewart et al, 1967; Hamilton, Lynch, and Reilly, 1969; Pollock et al, 1970) mucosae and the differences between the means are small (Rubin et al, 1960a; Shiner and Doniach, 1960; Chacko et al, 1961; Bayless et al, 1962; Jos, 1962; Madanagopalan et al, 1965; Stewart et al, 1967). The ranges of values for the two groups always overlap (Rubin et al, 1960a and b; Shiner and Doniach, 1960; Chacko et al, 1961; Cameron et al, 1962; Jos, 1962; Yardley et al, 1962; Madanagopalan et al, 1965) unless the controls are free from gastrointestinal disease, and even then their separation is not great (Stewart et al, 1967). At best the difference between the means is less than two-fold for surface cell height (Shiner and Doniach, 1960; Madanagopalan et al, 1965; Stewart et al, 1967), slightly more than two-fold for mucosal thickness 
(Shiner and Doniach, 1960; Stewart et al, 1967) and for length of villous epithelium (Madanagopalan et al, 1965), about three-fold for length of surface epithelium (Butterworth and Perez-Santiago, 1958) and for ratio of villous height to total mucosal thickness (Madanagopalan et al, 1965), and about four-fold for villous height (Madanagopalan et al, 1965).

Simple inspection with a light microscope shows that even normal surface epithelial cells vary considerably in height (Swanson and Thomassen, 1965) so that the selection of cells for measurement involves a considerable subjective element. This applies even with the cells on the sides of the villi in the middle third, the preferred site for measurement (Swanson and Thomassen, 1965; Stewart et al, 1967). Furthermore, meaningful measurements of 'villi' are hard to make in a mucosa which shows joining leafy villi, convolutions, or a convoluted mosaic appearance under the dissecting microscope (Holmes, Hourihane, and Booth, 1961; Booth, Stewart, Holmes, and Brackenbury, 1962), and impossible in one that is flat (Doniach and Shiner, 1957; Butterworth and Perez-Santiago, 1958; Shiner and Doniach, 1960; Stewart et al, 1967).

\section{Patients, Materials, and Methods}

Proximal jejunal biopsies were obtained during the routine investigation of patients suspected of having conditions liable to affect the small intestine, including adult coeliac disease and dermatitis herpetiformis. A Crosby capsule (Crosby and Kugler, 1957) fitted with a Kifa catheter (Frič and Lepšik, 1965) was passed with the aid of a polythene tube (Evans, Farrow, Harding, and Stewart, 1970) and advanced under fluoroscopic control into the first loop of the jejunum. All biopsies were taken several centimetres beyond the duodeno-jejunal junction. Because of a concurrent study involving electron microscopy, the specimens were fixed in gluteraldehyde buffered with sodium cacodylate. They were subsequently washed with sucrosecacodylate buffer and then stained with haematoxylin and eosin (H and $\mathrm{E}$ ), the periodic acid Schiff sequence, and haematoxylin Van Giesen.

The mucosal structure seen under the dissecting microscope was graded according to the classification of Holmes et al (1961) as subsequently modified (Booth et al, 1962). The histological appearances were classified according to the descriptions of Doniach and Shiner (Doniach and Shiner, 1957; Shiner and Doniach, 1960). Coeliac disease was diagnosed if the jejunal mucosa was flat or flat with mosaic on dissecting microscopy, showed 'subtotal villous atrophy' on histology, and subsequently improved when the patient was treated with a gluten-free diet. The control mucosae were taken from patients with functional diarrhoea, nutritional deficiencies, or chronic pancreatitis. Their biopsies showed finger- or leaf-like villi and normal histological features, including surface cell height (Stewart et al, 1967). The mean age of the control subjects was 41.4 years and that of the coeliac patients $41 \cdot 3$ years.

To measure the total cross-sectional areas occupied by the surface and by the crypt epithelium, a modification of the technique of television image analysis was used. The television image analyser was originally developed by Coyne at the Cyclotron Unit, Hammersmith Hospital for G. R. Massarella and others to quantitate lung histology (Williams, 1972a and b), and has also been used for studies of bone histology (Williams, 1972a) and radiology (Dickson, Paice, and Calnan, 1973) and immunofluorescent cells (Polak, Stagg, and Pearse, 1972). A black-and-white television camera scans the object to be examined (in our study, a drawing), and converts up to seven shades of grey into seven colours which are displayed on a television monitor. The colours are related to the light intensity at the respective parts of the object and not to their original colour. This picture is used in the calibration of the instrument. An analog computer processes the television signals and the results are displayed in numerical form. One of the measurements carried out by the instrument is the total area occupied by a given colour regardless of its shape, distribution, or number of parts. An automatic circuit calculates the mean of up to 256 readings. The technical details of the instrument are to be published elsewhere (Coyne, 1973). Because of some difficulty with the colours that we used initially to distinguish surface epithelium from adjacent crypts, we finally used only one colour, black, for the present study and put the two areas to be measured, the surface cells and the crypt cells, on separate drawings.

The drawings were obtained in the following manner. The H-and-E-stained sections of each biopsy were projected with a standard microprojector. From the enlarged image thus obtained, the epithelium was outlined on paper with a fine felt-tipped pen. The area occupied by the epithelium was taken to be that bounded by the luminal aspect (including the interior of a crypt) on the one hand and the basement membrane on the other. The junctions between surface and crypt epithelium were arbitrarily taken to be at the bases of the villi when those were present, and at the crypt mouths when villi were absent. The occasional small 
projections of cells seen at the bases of some villi were counted as crypt cells. Biopsies were accepted for study only if they were well orientated and had vertical sections through villi and crypts. Two Xerox copies were made of each drawing. On one copy the area occupied by the surface epithelium was filled in with black ink and on the other the area occupied by the crypt epithelium.

The television image analyser was used to measure the total area occupied by the black ink on each drawing. In order to standardize the measurements, the $1 \mathrm{~mm}$ scale of a stage micrometer was projected in association with each biopsy slide. To obtain an identical magnification of each section, the distance between the projector and the paper was adjusted until the scale exactly occupied a standard length previously marked on the drawing paper. The subdivisions of the scale were then drawn on the paper, and subsequently used in the standardization of the image analyser. Finally, for each biopsy the ratio between the area of the surface epithelium and that of the crypt epithelium was calculated. This will be referred to as the area ratio.

To make the study as consistent and objective as possible, one of us made all the drawings, another performed the television image analyses, and a third measured the heights of the surface cells without knowledge at the time of the patients' names, diagnoses, or treatment. The surface cell heights were measured with an eye-piece micrometer (Doniach and Shiner, 1957), 20 cells being measured in each biopsy.

\section{Results}

Twelve control and 12 coeliac mucosae were

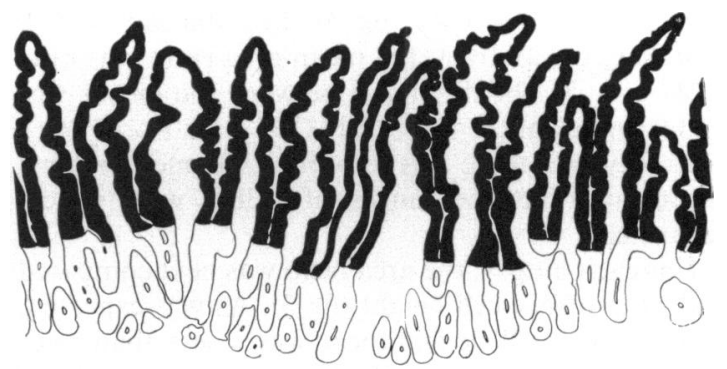

Fig 1 Drawing of surface and crypt epithelium of control jejunal mucosa.

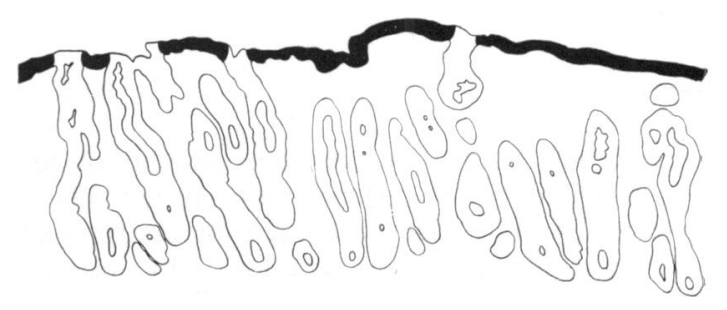

Fig 2 Drawing of surface and crypt epithelium of untreated coeliac jejunal mucosa.

examined. A typical example of the drawings for a control mucosa is given in fig 1 and for a coeliac mucosa in figure 2 . For brevity, only drawings with the surface epithelium blackened in are shown, and the outlines of the crypt epithelium. For the control mucosae, the mean area ratio $( \pm$ SD) of the surface epithelial area to the crypt epithelial

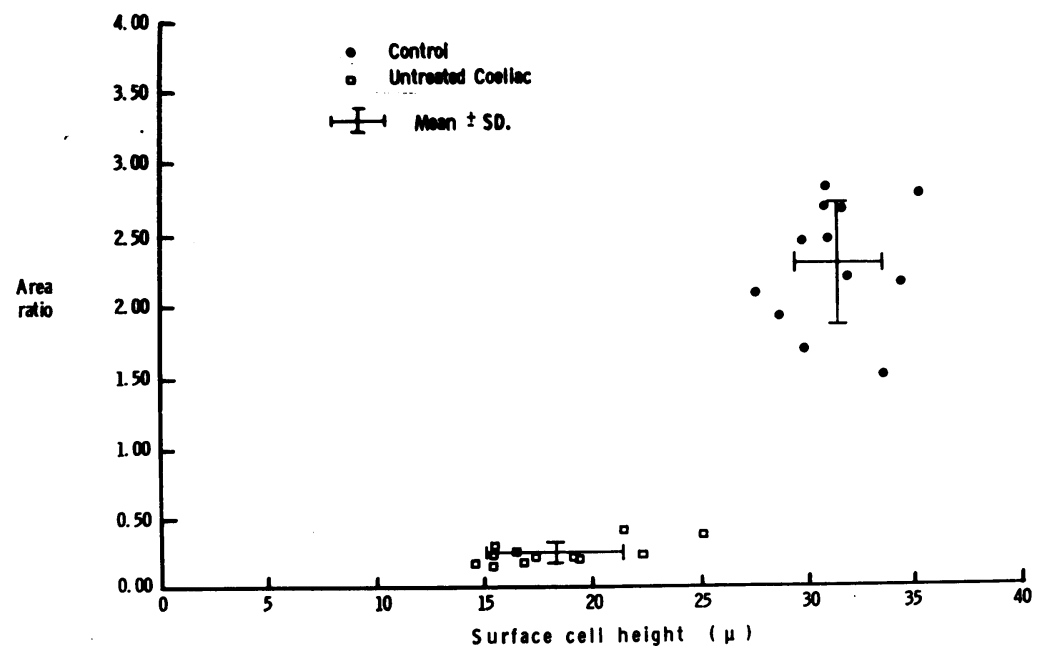

Fig 3 Area ratios and surface cell heights of control and untreated coeliac jejunal mucosae. 
area was $2.27 \pm 0.41$ (fig 3). For the flat coeliac mucosae, by contrast, the mean area ratio was only $0.24 \pm 0.07$. The difference between the means was highly significant $(t=16.391, D F=22, P<0.001)$. Not only was there this ten-fold difference between the means, but the ranges of values were widely separated.

For each biopsy, the area ratio was next compared with the surface cell height (fig 3). As was expected, with surface cell height there was a less than twofold difference between the means for control and coeliac mucosae, and the ranges for the two groups were almost continuous. This contrasted with the wide separation of both means and ranges achieved in the same biopsies with the area measurement technique.

\section{Discussion}

This new technique based on meaurements of the areas occupied by the surface and crypt epithelium distinguished quite clearly between the extremes of jejunal architecture, as exemplified by normal villi on the one hand and 'subtotal villous atrophy' on the other. The degree of separation achieved between control and untreated coeliac mucosae was greater than reported for any other method (Rubin et al, 1960a and b; Shiner and Doniach, 1960; Chacko et al, 1961; Bayless et al, 1962; Cameron et al, 1962; Jos, 1962; Yardley et al, 1962; Madanagopalan et al, 1965; Stewart et al, 1967). The superiority of the technique was confirmed in our own cases when the area ratios were compared with surface cell height, the most consistent (Shiner and Doniach, 1960; Yardley et al, 1962; Madanagopalan et al, 1965; Stewart et al, 1967; Pollock et al, 1970) of the existing measurements. The narrow range of values found with the present technique for the flat mucosae, together with the great difference between these and the control mucosae, gives plenty of room to follow the serial changes which occur in the coeliac mucosa as it recovers under the influence of a gluten-free diet. We have had no opportunity to compare ours with the recently reported point-counting technique of Dunnill and Whitehead (1972). However, their method gave a less than six-fold difference between the means for normal and untreated coeliac mucosae.

A possible source of error with this technique is the arbitrarily chosen line of demarcation between the surface and the crypt epithelial cells. There appeared to be no entirely satisfactory solution to this problem which has been well recognized since the work of Thurlbeck, Benson, and Dudley (1960) who used the ratio of villous height to crypt depth. They had difficulty in distinguishing between crypt and 'surface' epithelium, especially in abnormal mucosa. In the present study the same observer made all the drawings in order to minimize observer error in selecting this point of demarcation. He was not aware of the patients' names, diagnoses, or stage of treatment at the time of making the drawings. When villi were present the division was taken to be at their bases, any projection of cells between the villi being treated as crypt cells. When there were no villi the junction of surface and crypt cells was taken to be at the crypt mouths.

In normal mucosa the cells between the bases of the villi were called crypt cells but in flat mucosa the cells between the crypt mouths were called surface cells. If the cells between the bases of the villi had been taken as surface cells, because they were not inside the crypts, the difference between the ratios for normal and abnormal mucosae would have been even greater.

We emphasize that we do not propose this technique for the diagnosis of coeliac disease. Existing methods are adequate for this and much simpler. Our technique is intended for the measurement of minor changes in the mucosa such as those occurring during treatment of coeliac disease with a gluten-free diet. We also point out that, at present, it is a research technique only and must be modified and simplified before becoming generally applicable. However, future developments in the techniques of tissue staining and of television image analysis may make possible area measurements direct from the histological sections.

One of us (B.L.C.) is in receipt of a research grant from the North-West Metropolitan Regional Hospital Board. Miss Susan Robinson of the West Middlesex Hospital kindly drew figure 3.

References

Astaldi, G., Conrad, M., Ratto, L., and Costa, G. (1965). Measurement and features of normal jejunal mucosa by peroral biopsy. Panminerva med., (English edition), 7, 404-408.

Bayless, T. M., Yardley, J. H., Norton, J. H., and Hendrix, T. R. (1962). Adult celiac disease: rapid sequential changes in jejunal mucosa with alterations of dietary gluten. (Abstr.) J. clin. Invest., 41, 1344.

Bolt, R. J., Parrish, J. A., French, A. B., and Pollard, H. M. (1964), Adult celiac disease: histologic results of long-term low gluten diet. Ann. intern. Med., 60, 581-586.

Booth, C. C., Stewart, J. S., Holmes, R., and Brackenbury, W. (1962). Dissecting microscope appearances of intestinal mucosa. In Intestinal Biopsy (Ciba Foundation Study Group, No. 14), edited by G. E. W. Wolstenholme and M. P. Cameron, pp. 2-23. Churchill, London.

Butterworth, C. E. Jr., and Perez-Santiago, E. (1958). Jejunal biopsies in sprue. Ann. intern. Med., 48, 8-29.

Cameron, A. H., Astley, R., Hallowell, M., Rawson, A. B., Miller, C. G., French, J. M., and Hubble, D. V. (1962). Duodenojejunal biopsy in the investigation of children with coeliac disease. Quart. J. Med., 31, 125-140.

Chacko, C. J. G., Job, C. K., Johnson, S., and Baker, S. J. (1961). Histopathological changes in the upper jejunum in tropica ${ }_{1}$ 
malabsorption syndrome studied by transoral biopsy. Indian J. Path. Bact., 4, 203-213.

Coyne, M. B. (1973). In preparation.

Crosby, W. H., and Kugler, H. W. (1957). Intraluminal biopsy of the small intestine: the intestinal biopsy capsule. Amer. J. dig. Dis., 2, 236-241.

Dickson, R. A., Paice, F., and Calnan, J. S. (1973). The quantitative colour television image analyser: a new method of measuring bone density. J. Bone Jt. Surg., 55B, 359-368.

Doniach, I., and Shiner, M. (1957). Duodenal and jejunal biopsies II. Histology. Gastroenterology, 33, 71-86.

Dunnill, M. S., and Whitehead, R. J. (1972). A method for the quantitation of small intestinal biopsy specimens. J. clin. Path., 25, 243-246.

Evans, N., Farrow, L. J., Harding, A., and Stewart, J. S. (1970). New techniques for speeding small intestinal biopsy. Gut, 11, 88-89.

Frix, P., and Lepsik, J. (1965). Use of Odman-Ledin catheter and Seldinger wire with Crosby capsule. Gut, 6, 101.

Hamilton, J. R., Lynch, M. J., and Reilly, B. J. (1969). Active coeliac disease in childhood. Clinical and laboratory findings of forty-two cases. Quart. J. Med., 38, 135-158.

Holmes, R., Hourihane, D. O'B., and Booth, C. C. (1961). Dissecting microscope appearances of jejunal biopsy specimens from patients with "idiopathic steatorrhoea". Lancet, 1, 81-83.

Jos, J. (1962). La biopsie de la muqueuse intestinale chez l'enfant. In Etude des Syndromes de Malabsorption. Foulon, Paris.

Madanagopalan, N., Shiner, M., and Rowe, B. (1965). Measurements of small intestinal mucosa obtained by peroral biopsy. Amer. J. Med., 38, 42-53.

Polak, J. M., Stagg, B., and Pearse, A. G. E. (1972). Two types of Zollinger-Ellison syndrome; immunofluorescent, cytochem- ical and ultrastructural studies of the antral and pancreatic gastrin cells in different clinical states. Gut, 13, 501-512.

Pollock, D. J., Nagle, R. E., Jeejeebhoy, K. N., and Coghill, N. F. (1970). The effect on jejunal mucosa of withdrawing and adding dietary gluten in cases of idiopathic steatorrhoea. Gut, 11, $567-575$.

Rubin, C. E., Brandborg, L. L., Phelps, P. C., and Taylor, H. C., Jr. (1960). Studies of celiac disease. I. The apparent identical and specific nature of the duodenal and proximal jejunal lesion in celiac disease and idiopathic sprue. Gastroenterology, 38, 28-49.

Rubin, C. E., Brandborg, L. L., Phelps, P. C., Taylor, H. C., Jr., Murray, C. V., Stemler, R., Howry, C., and Volwiler, W.(1960). Studies of celiac disease. II.: The apparent irreversibility of the proximal intestinal pathology in celiac disease. Gastroenterology, 38, 517-535.

Shiner, M., and Doniach, I. (1960). Histopathologic studies in steatorrhea. Gastroenterology, 38, 419-440.

Stewart, J. S., Pollock, D. J., Hoff brand, A. V., Mollin, D. L., and Booth, C. C. (1967). A study of proximal and distal intestinal structure and absorptive function in idiopathic steatorrhoea. Quart. J. Med., 36, 425-444.

Swanson, V. L., and Thomassen, R. W. (1965). Pathology of the jejunal mucosa in tropical sprue. Amer. J. Path., 46, 511-551.

Thurlbeck, W. M., Benson, J. A., Jr., and Dudley, H. R., Jr. (1960). The histopathologic changes of sprue and their significance. Amer. J. clin. Path., 34, 108-117.

Williams, E. D. (1972a). Automated histoquantitation studies of bone. Proc. roy. Soc. Med., 65, 539-541.

Williams, E. D. (1972b). Personal communication.

Yardley, J. H., Bayless, T. M., Norton, J. H., and Hendrix, T. R. (1962). Celiac disease: a study of the jejunal epithelium before and after a gluten-free diet. New Engl.J. Med., 267, 1173-1179.

\section{The October 1973 Issue}

\section{THE OCTOBER 1973 ISSUE CONTAINS THE FOLLOWING PAPERS}

The effect of cholecystectomy on bile salt metabolism E. W. POMARE AND K. W. HEATON

Limits of the evocative pancreatic function test in the diagnosis of low-grade pancreatitis R. VAN DER HOEDEN, P. WETTENDORFF, AND A. DELCOURT

The abnormal lower oesophageal sphincter in pernicious anaemia RAYMOND L. FARRELL, OTTO T. NEBEL, ARTHUR T. MCGUIRE, AND DONALD O. CASTELL

The permeability of the small intestinal mucosa: A study using iron C. A. LOEHRY, D. PARISH, AND JUNE BAKER

Mucosal secretory IgA and secretory piece in adult coeliac disease R. J. SHINER AND JANET BALLARD

Electrical potential difference and sodium and potassium fluxes across rectal mucosa in ulcerative colitis C. J. EDMONDS AND DIANA PILCHER
The effect of a chemically defined diet on the faecal flora and faecal steroid concentration J. $\mathbf{S}$. CROWTHER, B. S. DRASAR, P. GODDARD, M. J. HILL, AND K. JOHNSON

Serum carcinoembryonic antigen in clinical disorders S. N. BOOTH, J. P. G. KING, J. C. LEONARD, AND P. W. DYKES

A case of active chronic hepatitis with painless erosive arthritis D. E. BARNARDO, B. VERNONROBERTS, AND H. L. F. CURREY

\section{Progress report}

Acute hepatic necrosis and fulminant hepatic failure B. RUEFF AND J.-P. BENHAMOU

The British Society of Gastroenterology

Notes and activities

Notes on books

Copies are still available and may be obtained from the PUBLISHING MANAGER, BRITISH MEDICAL ASSOCIATION, TAVISTOCK SQUARE, LONDON WC1H 9JR, price $87 \frac{1}{2} \mathrm{p}$ 